\title{
A tese de performatividade e 0 ambiente das ideias: o papel dos modelos formais em economia
}

The performativity thesis and the environment of ideas: the role of formal models in economics

\author{
Celso Neris Jr. \\ Universidade Estadual de Campinas \\ José Ricardo Fucidji \\ Universidade Estadual Paulista
}

\section{Resumo}

Este trabalho expõe a tese de performatividade da economia e a utiliza como argumento a respeito da influência que os modelos dos economistas têm no sistema econômico. Embora a tese de performatividade tenha sido alvo de críticas - sendo até considerada um modismo por alguns críticos -, sua versão fraca aponta que as construções teóricas podem ter efeitos sobre as práticas dos agentes na economia. Admitindo essa versão fraca, é importante discutir os motivos para a adoção de modelos formais, malgrado sua patente falta de realismo. Encontramos uma das razões nas instituições da economia e seus processos de legitimação epistêmica. Assumindo a possibilidade de que tal escotha possa colocar os economistas em um resultado ruim (lock-in) em relação ao objetivo de entender o sistema econômico real e nele atuar, o trabalho defende maior percepção ontológica na formulação e uso de modelos.

\section{Palavras-chave}

tese de performatividade; ontologia; modelos formais.

Códigos JEL B41; A11; A14. 


\section{Introdução}

O objetivo deste trabalho é discutir como os economistas influenciam a economia, como os métodos são escolhidos e que papel os modelos formais (instrumentos de representação e interpretação da realidade) têm nessa influência. A motivação para a discussão é dupla. Por um lado, a economia-como-disciplina (economics) na visão dominante (mainstream) se caracteriza (entre outras coisas) pela insistência no uso de modelagem formal como o veículo privilegiado para o conhecimento da economia-como-objeto (economy). Por outro lado, diversos economistas não mainstream (Colander et al., 2009; Hodgson, 2009; Lawson, 2009; Omerod, 2010; Vercelli, 2011) têm discutido a influência dos modelos formais da economics no funcionamento da economy, ${ }^{1}$ em suas interpretações da crise financeira de 2008. Torna-se relevante, dessa forma, entender a relação entre a possível performatividade da economia, a origem das ideias econômicas que se tornam dominantes e sua corporificação em artefatos (modelos e técnicas) acadêmicos que influenciam a economia.

Para cumprir esse objetivo, o trabalho está organizado como segue. $\mathrm{Na}$ seção 2, apresenta-se a tese de performatividade da economia, seus diversos sentidos e principais críticas. Essa maneira de apresentar a tese ajuda a lapidar o conceito de modo a aproveitá-lo ao objetivo do texto. Com isso, o sentido mais fraco de performatividade é admitido - viz., o de que os modelos, as teorias e as técnicas dos economistas influenciam a realidade social que analisam e interpretam. A seção 3 identifica a origem dos modelos da visão dominante nas instituições da ciência econômica; mais exatamente, em seus processos de legitimação epistêmica. Por fim, a seção 4 discute a relação entre os modelos e a realidade. Seguem-se as considerações finais na seção 5 .

\section{Performatividade da economia}

Os economistas acadêmicos representam e interpretam a economia predominantemente por meio de modelos teóricos, com seus pressupostos, predições, explicações e expectativas de resultado, frequentemente forma-

1 Para evitar anglicismos, doravante utilizaremos os termos "teoria" ou "ciência econômica" para denotar a "economics", e economia para denotar a "economy". 
lizados. Mais do que um modismo, a noção de performatividade procura explicar a interação entre os modelos (de representação e interpretação) econômicos e a realidade. Em seu sentido mais forte, performar envolve, dentre outras coisas, aproximar (e munido dos artefatos propícios, tornar semelhante) o mundo real do mundo do modelo dos economistas. Quer dizer, performar envolve mudar, mais do que observar o mundo (Mäki, 2013, p. 445). A noção de performatividade é derivada do filósofo J. L. Austin (1962) em seu trabalho sobre atos de fala e tem em Michel Callon e Donald MacKenzie seus principais proponentes.

Um enunciado performativo é um tipo específico de declaração ou expressão que estabelece o referente através do ato de proferi-lo (MacKenzie et al., 2007, p. 2-3). Por exemplo, ao dizer "eu peço desculpas", não se está relatando um estado de coisas já existente, mas sim produzindo um estado de coisas. Dizer "peço desculpas" é fazer um pedido de desculpas, sendo assim, é um enunciado performativo. A questão central é a maneira como as ações, as entidades e as representações estão entrelaçadas. Nesse sentido, o modo como se diz "eu peço desculpas" pode minar o efeito performativo se se adota um tom sarcástico ou se a expressão facial for de zombaria. De modo mais geral, as "condições de felicidade" 2 de um enunciado performativo são sociais, bem como linguísticas e corporais, como aponta Bourdieu (1991, p. 74-76). Na Idade Média, um monarca poderia tornar alguém fora da lei pelo simples fato de declarar que tal pessoa o era. No entanto, tinha o direito de fazê-lo somente se tivesse o "poder simbólico" (reconhecimento social) para isso.

Michel Callon, que trabalha no campo dos estudos da ciência, propôs-se a elucidar o caráter performativo da ciência econômica. Por "ciência econômica", Callon (2005, p. 9) entende "todas as atividades, acadêmicas ou não... que têm por objetivo entender, analisar ou equipar os mercados". Ela não é uma forma de conhecimento que apenas descreve um estado de coisas já existente, mas um conjunto de instrumentos e práticas que contribuem para a construção de ambientes, atores e instituições econômicas. Para Callon, a ciência econômica é uma parte da infraestrutura dos mercados modernos. Ela enquadra, molda e formata a economia, em vez

2 Condições de felicidade são as circunstâncias adequadas (Austin, 1962, p. 14-15) para tornar bem-sucedido o enunciado performativo. Neste sentido, um enunciado performativo pode ser feliz ou infeliz. Já enunciados "constatativos" indicam (constatam) um estado de coisas que pode ser verdadeiro ou falso 
de simplesmente observar como ela funciona. Segundo Callon (2010, p. 163), dizer que a ciência econômica, com sua multiplicidade "de arcabouços de análise e modelos teóricos desenvolvidos, contribui para a construção do objeto estudado" significa implicitamente reivindicar que não há uma única "forma de organizar o sistema econômico e, mais do que isso, de organizá-lo satisfatória ou mesmo eficientemente". Sua preocupação é com uma "forma de organização" específica dentro da economia (o mercado). Essa maneira de ver o leva a uma afirmação (pouco sustentável) de que o sistema econômico está imerso não na sociedade, mas na ciência econômica (Callon, 1998, p. 29-30).

A teoria neoclássica e seu homo economicus é o objeto de estudo de Callon. Para ele, o homo economicus não existe, conquanto ele "não seja uma realidade a-histórica; ele não descreve a natureza oculta do ser humano. Ele é o resultado de um processo de configuração" (Callon, 2005, p. 51). A ciência econômica é o meio pelo qual ele pode existir, uma vez que ela "o formatou, enquadrou e equipou com as próteses que o auxiliam em seus cálculos". Dois elementos intrinsecamente ligados são destacados: (i) as demonstrações teóricas que descrevem padrões comportamentais; e (ii) as instituições socioeconômicas que criam as condições para aqueles padrões. Ao descrever eventos e as circunstâncias em que ocorrem, as demonstrações teóricas evocam (mais ou menos explicitamente) as instituições socioeconômicas que provocam os acontecimentos descritos (Santos; Rodrigues, 2009, p. 987). Nessa interpretação, as instituições socioeconômicas são arranjos artificiais de elementos heterogêneos que incluem "seres humanos, mas também... próteses, equipamentos técnicos, algoritmos, etc., que são cuidadosamente ajustados um ao outro, de modo a produzir os eventos descritos nos enunciados" (Callon, 2005, p. 4).

Há dois sentidos de performatividade em Callon. No sentido forte, os esforços de engenharia dos economistas conseguem produzir a realidade representada na teoria econômica. Eles o fazem através da concepção de determinadas instituições socioeconômicas de mercado que produzem os padrões de comportamento postulados ou previstos pelas teorias econômicas. No sentido fraco, a ciência econômica é performativa sempre que

3 Não por acaso, Callon (2010, p. 163) trata o trabalho de Nelson e Winter (1982) como proponente de uma forma de organização diversa - na qual o mercado está "organizado em torno de uma lógica sistêmica de inovação e criação de novos recursos" - da representada nos modelos tradicionais. 
é utilizada na construção do mercado, contribuindo, com isso, para a mercantilização da vida social, ou quando auxilia os agentes econômicos a calcular seus interesses em circunstâncias particulares. Ambos os sentidos têm em comum o fato de evocarem a criação de mercados. No entanto, enquanto o primeiro implica a existência de uma agência movida pelo autointeresse, que deliberadamente produz mudanças no sistema econômico (Callon, 2007, p. 346), o segundo refere-se à concepção mais sustentável do "programa antropológico neoclássico", de mercantilização da vida social e substituição de relações pessoais pela troca impessoal, mediante a introdução do cálculo racional (Callon, 2007, p. 343).

A análise de Callon procura captar a interação entre teoria e realidade e tece algumas considerações a respeito da teoria econômica neoclássica. De fato, é possível considerar que ela gera padrões comportamentais (e.g., a crença no estado de equilíbrio, na maximização do bem-estar sob certos pressupostos). ${ }^{4}$ Tal projeto ontológico, porém, extrapola até os limites do "econômico". Por exemplo, Becker (1992, p. 386) afirma "o comportamento [utilitarista] é motivado por um conjunto muito mais rico de valores e preferências". Para ele, o indivíduo "maximiza o bem-estar conforme ele o entende, seja de modo egoísta, altruísta, leal, rancoroso ou masoquista". Isso lhe permite analisar, por exemplo, crime, assuntos intrafamiliares e suicídio - coisas que não possuem relação com a troca impessoal nos mercados. Ademais, há uma forte denúncia que tal perspectiva utilitarista ajudou a sustentar a ideologia e a prática da ganância irresponsável na crise de 2008 (Hodgson, 2010, p. 402).

Donald MacKenzie parece ser mais claro conceitualmente do que Callon. Para MacKenzie et al. (2007, p. 2), a ciência econômica trabalha na economia de uma maneira que está em desacordo com a concepção generalizada de ciência como uma atividade cujo único objetivo é observar, estudar e conhecer o mundo. Ela oscila entre representação e ação, entre ciência e política, entre a pesquisa acadêmica e a intervenção política, tanto como disciplina quanto nas carreiras de muitos economistas. Segundo MacKenzie (2006, p. 29), reivindicar que a ciência é performativa é argumentar que ela cria coisas, mais do que simplesmente descreve (com maior ou menor grau de precisão) uma realidade externa que não é afetada por

4 Contudo, Santos e Rodrigues (2009, p. 999) lembram que "os agentes não se podem tornar máquinas atomísticas de cálculo no mercado. Os mercados nunca deixam de ser comunidades morais nas quais as normas e valores sociais também são considerados". 
ela própria. Com isso, a formação da economia pela ciência pode ser vista como um triunfo para as verdades descobertas pela disciplina ou pode ser condenada como a imposição prejudicial de uma visão de mundo abstrata e irreal à economia real. Sobre esse ponto, Santos e Rodrigues (2009, p. 986) ressaltam que, na tese de performatividade, teorias, modelos, instrumentos e práticas econômicas estão agindo sobre a economia enquanto estão sendo utilizadas para observar, medir, prever, explicar ou regular o seu funcionamento. Isso explicaria por que a economia estaria operando de forma cada vez mais de acordo com as teorias econômicas (se esse for o caso). Em suma, nessa perspectiva, a utilização de algum aspecto da ciência econômica nos processos econômicos afeta a forma como os recursos são produzidos, organizados, trocados e consumidos.

Algumas variações conceituais podem ser encontradas em MacKenzie (2006, p. 16-20). Segundo ele, a performatividade da economia pode ser: (i) genérica: um aspecto da ciência econômica (uma teoria, modelo, conceito, procedimento, conjunto de dados, etc.) é usado por participantes dos mercados, formuladores de políticas, reguladores e assim por diante; (ii) efetiva: a utilização de um aspecto da ciência econômica possui um efeito sobre o processo econômico; (iii) barnesiana: ${ }^{5}$ a utilização de um elemento da ciência econômica cria processos econômicos mais do que os descreve. No caso da utilização de um modelo da ciência econômica, por exemplo, suas implicações normativas podem promover alterações nos processos econômicos, que passam a corresponder melhor a ele. O sentido forte da performatividade barnesiana, no qual a utilização de um modelo (ou algum outro elemento da ciência econômica) faz com que ele seja mais verdadeiro, aumenta a possibilidade do seu inverso - a contraperformatividade - a utilização prática de uma teoria ou modelo pode alterar os processos econômicos de modo a torná-los menos parecidos com sua descrição pela ciência econômica.

MacKenzie vai além da definição de Callon, que analisa apenas a formação dos mercados. No entanto, parece sustentar uma postura conservadora e convencional sobre a ciência econômica quando diz que a formação

5 Em alusão ao sociólogo Barry Barnes (1983, 1988), orientador de Donald MacKenzie, que enfatizou o papel central na vida social de self-validating feedback loops. Se um monarca absoluto designa Robin Hood um "fora da lei", então Robin é um fora da lei. Alguém será um "líder" se seus seguidores os considerarem como tal. Um disco de metal, um pedaço de papel, ou um registro eletrônico é dinheiro se, coletivamente, podemos tratá-lo como unidade de conta, meio de troca e reserva de valor. 
da economia pela ciência pode ser vista como triunfo ou condenação. Nesse raciocínio, por exemplo, o modelo dominante da economia tornar-se-ia dominante por criar o mundo à sua imagem. Não é possível falar da realidade das teorias, ou da sua verdade, de maneira ex ante, pois essas, ao serem utilizadas, participam na definição e na criação do que é verdadeiro ou real (Felin; Foss, 2009, p. 676). Se os modelos criam realidades, qualquer tentativa de identificar a sua fraqueza ontológica, metodológica ou epistemológica é inútil (Hodgson, 2010, p. 403). Esse autor afirma que isso mina muitas críticas às teorias econômicas, ainda que seja inegável que as ideias possuem influência significativa sobre a realidade (Hodgson, 2010, p. 401).

Algumas vezes a intervenção da ciência econômica sobre a realidade é operada diretamente pelos economistas, como ocorre quando economistas acadêmicos são contratados como empregados ou consultores de uma determinada empresa, mercado, governo ou órgão regulador. Em outros casos, os economistas produzem ferramentas e instrumentos usados pelos agentes do mercado ou formuladores de política, como é o caso da fórmula de precificação de opções do modelo Black-Scholes-Merton (MacKenzie et al., 2007, p. 9; MacKenzie, 2006, p. 6-7). Quando, liderados por Milton Friedman, foram chamados a treinar economistas da Universidade Católica do Chile entre 1955 e 1964, como parte de um programa da Guerra Fria "para combater um viés esquerdista percebido na economia chilena" (MacKenzie, 2006, p. 16), os economistas da Escola de Chicago não apenas se limitaram a analisar a economia chilena, mas também a reconstruí-la de acordo com os princípios do livre mercado e das prescrições monetaristas.

Uma tentativa de salvar o conceito das críticas pertinentes que tem recebido ${ }^{6}$ talvez seja conceber que performar é moldar a economia com as características dos modelos de representação e interpretação da ciência econômica, algo que pode ser feito de maneira direta pelos economistas, ou indireta por aqueles que aprenderam ou são influenciados por alguma teoria e exercem alguma relevância nos meios em que atuam. Essa teoria, em geral, é a aceita como dominante em determinado ambiente acadêmico, não implicando necessariamente que ela seja a mais verda-

6 Elas dizem respeito, principalmente, ao sentido forte. Mäki (2013, p. 448-9, 452) argumenta que o conceito é mal definido em Callon e MacKenzie, tornando-se um termo "guarda-chuva" para diversos significados. Isso engendra dois problemas: (1) distorce o sentido original do conceito em Austin; e (2) confunde os elementos de performatividade genuína (i.e., de relações constitutivas entre objetos) com outras formas de influência (causal) entre a ciência econômica e a economia. 
deira ou realista ex-ante. Ela pode moldar comportamentos de modo que os resultados previstos se confirmem, mas também pode gerar resultados contrários aos previstos. Com isso, a ciência econômica pode ser colocada em prática, e suas propostas, implementadas por decisões e políticas específicas, mas também pode se difundir pelo uso de determinados modelos e, eventualmente, introduzir processos de irreversibilidade e lock-in. O que implica dizer que performar pode ser tanto uma atitude deliberada quanto inconsciente. Há limites fundamentais nos modelos, a respeito da maneira como os agentes são concebidos pela teoria e se esses agem e pensam da maneira representada na teoria. A ciência econômica pode performar a economia de modo a fazer com que os agentes pensem (conscientes ou inconscientemente) como a teoria. Mas é necessário salientar que, mesmo na teoria mainstream, o agir e o pensar dos agentes pode corresponder a uma questão de contexto institucional e tecnológico sobre o qual a teoria econômica não tem impacto direto (e.g., as preferências individuais dadas ou as decisões em engenharia, baseadas em critérios técnicos).

A importância da tese da performatividade da ciência econômica pode ser ilustrada no tratamento da incerteza. A teoria neoclássica não considera o papel da incerteza presente na decisão de investir. $\bigcirc$ estado de ânimo ${ }^{7}$ do investidor é condicionado pelo conhecimento que ele possui acerca do futuro; na visão pós-keynesiana, porém, é uma disposição otimista em relação à incerteza, conforme enfatizam Dow e Dow (2011, p. 8, 16) e Dequech (1999, p. 420, n. 12). Tal conhecimento é condicionado pelo contexto social do agente. Assim, "a percepção de incerteza pode inclusive ser negativamente afetada pela existência de teorias que negligenciam a incerteza fundamental. Um ponto importante a esse respeito é que os economistas influenciam o modo como os não-economistas veem a realidade. A visão mainstream da economia acadêmica negligencia a incerteza" (Dequech, 1999 , p. 422). Sendo assim, alguns tomadores de decisão podem adotar a visão de "equivalentes de certeza", por exemplo, "por estudarem economia ou administração ou por empregarem como funcionários ou consultores pessoas que foram ensinadas na visão mainstream" (idem). É neste sentido que as ideias dos economistas influenciam o comportamento dos agentes econômicos e podem mudá-lo de diversas formas. Segundo Palley (1993, p. 7-8), "as construções teóricas dos economistas mudam a própria economia, $7 \bigcirc$ papel do estado de ânimo (animal spirits) não importa apenas à esfera financeira, mas também às esferas produtiva e tecnológica. Sobre esse ponto, ver Dow e Dow (2011). 
e, quanto mais influentes na sociedade os economistas forem, mais provavelmente a ciência econômica provocará mudanças de comportamento". Vista dessa maneira, a agenda de pesquisa da performatividade não é incompatível com o que propõem Santos e Rodrigues (2009, p. 999), para os quais uma tarefa importante seria "identificar os mecanismos pelos quais os participantes da ciência econômica moldam a vida social". E pode lançar luz, além disso, sobre como as teorias se tornam dominantes.

\section{Das ideias às instituições da economia}

Para construir determinado modelo de representação e interpretação da economia, os economistas teóricos partem de pressupostos que, segundo cada concepção, sejam boas aproximações da realidade, ou possam gerar boas predições ou ainda que tenham implicações teóricas interessantes e sejam passíveis de manipulação (Sugden, 2002; Morgan, 2012, caps. 1 e 10). Essa grande variedade de motivações e de estratégias de modelagem implica, conforme a seção anterior, maneiras diferentes pelas quais as ideias dos economistas podem influenciar a economia.

Keynes (1936, p. 383) já alertara sobre o poder das ideias dos economistas em sua Teoria Geral:

As ideias dos economistas e dos filósofos politicos são mais poderosas do que normalmente se percebe, tanto quando estão certas quanto quando estão erradas. De fato, o mundo é governado por pouco mais do que elas. Os homens pragmáticos, que se creem isentos de quaisquer influências intelectuais, usualmente são escravos de algum economista morto.

Contudo, como Palley (2012, p. 9) ressalta "a tragédia das ideias econômicas ruins é que, uma vez que dominam o imaginário da sociedade, torna-se quase impossível persuadir as pessoas a abandoná-las".

As análises dos economistas normalmente se originam de suas visões de mundo. Schumpeter (1954, p. 41-2, 561-2) afirma que o esforço analítico é direcionado por um "ato cognitivo pré-analítico", que ele chama de "visão" (por vezes, nomeia também de "concepção"). Para ele, o trabalho analítico se inicia com o material fornecido pela visão acerca das coisas, sendo que essa visão é "ideológica por definição". Para ele, as "regras de procedimentos" que aplicamos em nosso trabalho analítico são também influenciadas pela ideologia e sujeitas, tal como a visão, às paixões dos analistas. Isso tende a gerar erros, evidentemente. A "caixa de ferramentas" 
do economista (seu conjunto de teorias, modelos e instrumentos) poderia, em princípio, ser analisada sem esse elemento pré-cognitivo ou ideológico - por seu valor em si (p. 15). No entanto, o próprio Schumpeter (1954. p. $5,12,13)$ parece não confiar nessa possibilidade.

Existem elementos além da ideologia que influenciam as opiniões dos especialistas. Michelle Baddeley afirma que, quando as opiniões são formadas sob condições de incerteza, a opinião tende a ser inevitavelmente subjetiva. Em economia e finanças, isso é particularmente verdade, uma vez que a endogeneidade reflete o papel causal das crenças, por exemplo, de profecias autorrealizáveis sobre cotações de títulos. Em situações de incerteza, as pessoas empregam heurísticas e regras de comportamento para guiar sua interpretação dos eventos, o que acarreta problemas de "viés cognitivo, incluindo vieses de grupo, que ocorrem quando as crenças tendem a coincidir com as opiniões prévias de outros, criando fenômenos de manada e dependência da trajetória" (Baddeley, 2013, p. 35). Acadêmicos e outros especialistas podem, consciente ou inconscientemente, seguir consensos de grupos. $\bigcirc$ amplo apoio de uma hipótese ou teoria pode validá-la e, de acordo com os modelos bayesianos de aprendizagem social, ela pode ter maior probabilidade de ser verdadeira. No entanto, problemas ocorrem quando esse consenso reflete motivações alheias ao conhecimento e à busca da verdade, o que pode implicar excesso de peso a uma teoria "popular", mesmo em face de evidências objetivas contrárias (Baddeley, 2013, p. 36).

Errar de maneira coletiva por conta de crenças equivocadas é algo concebível em uma disciplina caracterizada pelo uso de modelos, que são uma construção social (Mäki, 2002, p. 23). A economia como uma disciplina científica é, entre outras coisas, uma questão de interação social entre os economistas, e entre economistas e outras pessoas, como estudantes, outros cientistas sociais, cientistas naturais, órgãos de gestão universitária, políticos e meios de comunicação. Essas interações acontecem em uma estrutura social mutável. ${ }^{8}$ A história da ciência oferece exemplos de erro coletivo, sugerindo a possibilidade de que qualquer grau de consenso existente na ciência econômica, em determinado momento, a respeito de um determinado tema, pode induzir a erro, no sentido de que o mundo não é o que se acredita ser coletivamente (Mäki, 2002, p. 25).

8 Mäki (2013, p. 450-1) propõe que a economia pode performar a ciência econômica, invertendo a performatividade de Callon e MacKenzie - mas ainda assim tem reservas sobre a tese de performatividade. 
Uma maneira de sistematizar as interações e o ambiente social no qual se originam as ideias é discutir, ao menos brevemente, as instituições da economia (e.g., Maki, 2002; Hodgson, 2009; Dequech, 2014). O estudo mais conhecido em economia sobre instituições - e até mesmo premiado com a honraria mais elevada da profissão - trata-as como as regras do jogo em uma sociedade ou, mais formalmente, como os constrangimentos humanamente concebidos que moldam a interação humana. Nessa perspectiva, as instituições reduzem a incerteza por proverem uma estrutura para a vida cotidiana (North, 1990, p. 3-5). Utilizando essa abordagem, North busca explicar o crescimento econômico em períodos longos. As instituições são as regras do jogo, e as organizações e os empresários, os jogadores; as organizações "são formadas por grupos de indivíduos ligados por algum propósito comum para atingir certos objetivos" (North, 1994, p. 361). No entanto, há uma deficiência nessa abordagem. Hodgson (2006, p. 10) argumenta que as organizações são estruturadas por atores individuais, muitas vezes com objetivos conflitantes. Assim, o tratamento dado por North à organização como um ator social tende a ignorar o potencial conflito entre os indivíduos que a constituem. Para entender o caráter institucional da economia-como-disciplina, é interessante um conceito que dê espaço à diversidade de ideias e visões, em lugar da interpretação de organização como uma estrutura monolítica de North.

Os autores da tradição de Veblen e Commons sugerem tratar as instituições como um tipo especial de estrutura social que possuem o potencial para mudar agentes, incluindo mudar seus propósitos e preferências. Instituições são sistemas de regras estabelecidas e dominantes (prevalecentes) que estruturam as interações sociais (Hodgson, 2006, p. 1). A durabilidade das instituições decorre do fato de que elas podem criar expectativas estáveis do comportamento dos outros. São dependentes dos pensamentos e das atividades dos indivíduos, mas não são redutíveis a eles e podem constranger ou habilitar pensamentos e/ou comportamentos. As representações mentais de uma instituição ou suas regras são partes constitutivas da instituição, uma vez que a instituição só pode existir se as pessoas possuem crenças particulares e relacionadas a atitudes mentais (Searle, 1995, 2005). Uma instituição é um tipo especial de estrutura social que envolve regras normativas potencialmente codificáveis de interpretação e comportamento.

As instituições da ciência econômica são as regras do jogo: elas consistem de estruturas que se relacionam com incentivos e recompensas, 
educação e emprego, publicação e consulta de especialistas, agenda de temas e padrões de avaliação (Mäki, 2002, p. 22). As instituições da ciência econômica moldam os valores e os objetivos da prática de economistas e, assim como outras instituições, estão sujeitas a alteração. Elas variam entre comunidades de praticantes das diferentes correntes do pensamento econômico. Dequech (2007-2008, p. 281) divide-as em categorias sociológicas, compreendendo mainstream e não mainstream. Pare ele, "a mainstream da ciência econômica é o que é ensinado nas universidades e nas faculdades de maior prestígio, o que é publicado nos periódicos mais bem classificados, que recebe recursos das fundações de pesquisa mais importantes e os prêmios mais aclamados". Usando a definição anterior de instituições, uma vez que as instituições da economia-como-disciplina possuem as próprias regras, convenções e normas sociais, elas afetam seus praticantes e interagem com a realidade econômica. Neste caso, é importante incluir na caracterização desse ambiente os "modelos mentais socialmente compartilhados", pois, "quando tratamos de ideias em uma disciplina acadêmica, assim como as ideias entre agentes e tomadores de decisão, todos esses tipos de ideia podem ser guiados por regras que são compartilhadas por razões sociais" (Dequech, 2014, p. 524).

Nem sempre uma instituição é seguida conscientemente. A legitimidade de uma instituição pode torná-la mais aceitável do que uma alternativa desviante. Por sua vez, a legitimidade pode ser entendida como a compatibilidade com alguns valores socialmente aceitos (Dequech, 2013, p. 95). O legítimo é aquilo que é considerado certo, adequado ou semelhante, de acordo com valores específicos. Dinamicamente, legítimo é aquilo que quer permanecer inquestionável ou sobrevive a testes de legitimidade, ou seja, o que, depois de algumas dúvidas ou críticas terem sido levantadas a seu respeito, ainda é considerado certo, apropriado. A legitimidade pode ser de diferentes tipos, assim como os valores em que se baseia. Na discussão das instituições, pelo menos três tipos de legitimidade são especialmente interessantes (Dequech, 2009, p. 73; 2013, p. 95-96), a saber, legitimidade moral, política e epistêmica. Em especial, o tratamento da legitimidade epistêmica é destacado por Dequech (2014, p. 526) como particularmente relevante para o caso das ideias.

Um conjunto institucional de regras de pensamento pode ser o modelo dominante, o mais prestigiado por um determinado grupo e possuir, com isso, legitimidade epistêmica. Exemplos bem fundamentados de valores 
epistêmicos são: compatibilidade com a evidência empírica, consistência, rigor e relevância (Dequech, 2009, p. 73), características cultivadas na vida acadêmica. Ao serem aceitas por mais e mais pessoas, por outros canais de transmissão de determinadas regras de pensamento percebidos como epistemicamente (intelectualmente) legítimos - periódicos profissionais, palestras, seminários, que compartilham informações e opiniões de economistas prestigiados ou influentes -, essas características se perpetuam em um processo de autorreforço. Como ressalta Dequech (2014, p. 526), "a percepção da legitimidade epistêmica nas ideias em parte depende do prestígio das pessoas que defendem estas ideias e do prestígio da universidade à que elas estão associadas". 9

As sanções sociais e a incerteza estão dentre as explicações para a conformidade com as regras de pensamento e comportamento existentes (Dequech, 2014, p. 526-7). Podem existir diferentes alternativas a se acompanhar em termos de ideias; no entanto, seguir algumas delas pode excluir o praticante - especificamente, o economista acadêmico pode ser preterido nas premiações mais importantes e no financiamento de pesquisas, ou seja, pode torná-lo não mainstream. Por isso, os economistas podem optar por não adotar a alternativa desviante. Outros optam por imitação, em razão de assimetrias informacionais - um está mais bem informado do que o outro, como é o caso destacado por Baddeley (2013, p. 35) de pesquisadores jovens em relação aos experientes.

O caminho para o desviante é difícil. Para Dequech (2014, p. 530), "o empreendedorismo intelectual envolve desafios em geral similares aos enfrentados pelo inovador em tecnologia. Há a pressão dos hábitos de pensamentos estabelecidos, à qual é difícil escapar. Isso ajuda a explicar por que as ideias inovadoras vêm, com frequência, de outras disciplinas". A teoria que trata da mudança tecnológica fornece, assim, alguns elementos para entender o que acontece ao acadêmico desviante.

A busca por espaço de determinada abordagem teórica dentro de uma comunidade de praticantes pressupõe um intenso trabalho de aprendiza-

9 Paula et al. (2003, p. 570-71) apresentam alguns dos fatores que conferem validação às teorias dominantes, que em parte se aproximam do que discutimos aqui, a saber: (i) pela aparente capacidade de responderem aos desafios colocados pela realidade concreta; (ii) pela sintonia que apresentam com os interesses das classes dominantes; (iii) pela capacidade que apresentam de se deixarem simplificar e padronizar; (iv) pelo investimento massivo e permanente em instrumentos e práticas de sua reiteração e divulgação; e (v) por atribuírem a si mesmas o monopólio da verdade científica, manifestado através do uso da formalização matemática. 
do e de busca por aceitação. Para isso, é necessário que outros adotem as novas ideias para que a abordagem possa ser melhorada e obter retornos crescentes de adoção. Ser mainstream exige certo empreendedorismo acadêmico. O empresário schumpeteriano é uma boa referência nesse caso. Knudsen e Swedberg (2009) resgatam duas contribuições importantes do conceito do empresário schumpeteriano. O primeiro é o de novas combinações, e o segundo, o de resistência ao empreendedorismo (cf. Schumpeter, 1934, p. 65-66, 80-1, 85-7).

Quanto às novas combinações, o processo econômico pode ser organizado de acordo com critérios produtivos e tecnológicos diferentes em uma sociedade capitalista, já que "a lógica econômica prevalece sobre a tecnológica" (Schumpeter, 1934, p. 14-15). As novas combinações, que consistem em utilizar os insumos de modo diferente, é algo que tem sido muito empregado por economistas acadêmicos em suas teorias, como atestam diversas análises (Dequech, 2003; Davis, 2007; e, particularmente, a Parte I de Davis; Hands, 2011).

Um dos efeitos da interdisciplinaridade, segundo Abramovay (2004, p. 44), é a "virada cognitiva" nas ciências sociais, que consiste em questionar uma espécie de princípio universal da conduta humana (o homo economicus), que torna o comportamento humano a-histórico e, de certa forma, a-social. Romper o status quo não é trivial, uma vez que existem fortes incentivos para mantê-lo e resistência ao novo. Para Schumpeter (1934, p. 86; Knusden; Swedberg, 2009, p. 4-6), a resistência ao novo pode ser associada a três motivos: (i) deve-se fazer o que a tradição manda na vida cotidiana (rotina); (ii) as pessoas costumam inclinar-se negativamente ao novo (psicologia); e (iii) além de impedimentos legais ou políticos, as pessoas mostram determinada hostilidade àqueles que tomam caminhos diferentes dos usuais (ambiente social). ${ }^{10}$

10 Como apontado por um parecerista, é interessante o paralelo com a explicação de Vinca Bigo (2008, p. 538-544) para a insistência no formalismo como único veículo epistemológico legítimo pelos economistas mainstream. Para esta autora, com base na teoria psicanalítica das relações objetais, a insistência em tais métodos decorre de mecanismos de defesa contra a ansiedade produzida nos primeiros meses de vida da criança pela separação dos cuidadores e da insegurança que se lhe segue. Tais mecanismos envolvem fantasias de supremacia e fantasias de predição, a fim de recuperar a segurança. Tais fantasias ecoam nas práticas dos economistas mainstream, uma vez que eles repetem padrões adquiridos na infância para lidar com a ansiedade. A autora, seguindo a abordagem da economia feminista, afirma que essas práticas são mais comuns no gênero masculino, uma vez que a formação da identidade de meninos e meninas é diferenciada. Tais práticas envolvem a discriminação dos métodos não formalistas como inferiores (dominação epistemológica) e a insistência em tais métodos (ape- 
Os cientistas podem deixar de perseguir objetivos epistêmicos, como informações verdadeiras sobre o mundo, e procurarem seus interesses particulares ou coletivos, tais como prestígio, credibilidade, fama, dinheiro ou o status da profissão (Mäki, 2002, p. 25). Saber se as crenças de uma comunidade científica são verdadeiras é uma questão diferente de saber como elas foram geradas. Por conta disso, Mäki (2002, p. 26) defende que o conceito de "conhecimento" deve incluir a noção de verdade como um ideal regulatório, em vez da noção mais difundida de "crença coletiva". Para ele, esta é a "versão realista" da ideia de que a verdade é construída socialmente. Para isso, as instituições da economia devem ser concebidas de forma a maximizar a probabilidade de que o conhecimento econômico publicado e ensinado nos ajude a atingir a máxima verossimilitude (truthlikeness) ${ }^{11}$ relevante de nossas crenças em relação à forma como a economia funciona (Mäki, 2002, p. 26).

\section{Os modelos e a economia que eles representam}

Na moderna mainstream, um dos valores acadêmicos mais altamente prezados é o de que as teorias e os modelos devem ser expostos, obrigatoriamente, em linguagem formal manipulável para serem considerados parte do corpo de conhecimento aceito. $\bigcirc$ advérbio "obrigatoriamente" denota a doutrina do formalismo. Essa é uma das características definidoras do trabalho realizado pela mainstream, mesmo que diversos outros aspectos tenham sido relaxados ou abandonados ao longo das últimas décadas (Lawson, 1997, p. 86-107; Davis, 2007; Bigo 2008). A questão é saber até que ponto os modelos formais performam a economia. Existem diversas indicações dessa influência. Hoover (2012) mostra como os macromodelos novo-clássicos e novo-keynesianos foram incorporados às regras de decisão dos policy makers nos EUA. Vercelli (2011) afirma que tais modelos contêm supostos que reforçam a ideologia de laissez-faire dos policy makers e do público, de

sar do seu insucesso) para se obter algum tipo de predição e controle sobre a incerteza. Esta última prática implica considerar um mundo aberto, relacional e transformável como passível de fechamento (delírio ontológico). Esta explicação, embora complementar, está distante da explicação institucional, muito mais direta, que tentamos aqui (ver também Bourdieu, 1976). 11 "Truthlikeness" poderia ser traduzida como "aproximação da verdade". Trata-se de um conceito já discutido por Santo Agostinho no século IV e introduzido na discussão filosófica moderna por Popper (ver Niiniluoto, 1999, p. 64-78 para a exposição da lógica formal). 
modo que, a partir dos anos 1980, apenas modelos microfundamentados passaram a ser aceitos. Colander et al. $(2009$, p. 7) vão ainda mais longe e afirmam que os modelos de expectativas racionais supõem que as expectativas dos agentes são forçadas (sic) a se harmonizar com a estrutura dos próprios modelos.

Tony Lawson defende que os métodos formais são bastante inadequados para a tarefa de iluminar fenômenos sociais, se admitirmos que o principal objetivo da pesquisa econômica é a iluminação da realidade econômica - é explicar e compreender o mundo socioeconômico real, tendo o objetivo de perseguir a "verdade" como ideal regulatório. Segundo sua interpretação, é provável que alguns economistas se utilizem da matemática na economia, não por acreditarem que seja um método adequado, mas por algum critério meramente pragmático, ou talvez pela elegância dos modelos, ou ainda para demonstrar que sabem utilizá-la (Lawson 2002, p. 76; 2003, cap. 10).

Os mundos expressos em tais modelos parecem ter pouca ou nenhuma relação com o tipo de mundo em que vivemos ou poderíamos viver. Os pressupostos comportamentais dos modelos da mainstream geralmente retratam um ideal de ser humano onisciente, sempre racional (otimizador), entre outras idealizações, admitidamente falsas, empregadas meramente para facilitar a tratabilidade matemática. Essa corrente emprega o dedutivismo ${ }^{12}$ como método de inferência, o que gera problemas, em razão da dificuldade de aplicar e entender a relação entre modelos idealizados e realidade econômica. Os métodos de modelagem utilizados pelos economistas exigem, para a sua eficácia, que a realidade que analisam seja um sistema fechado, quando na verdade o mundo social é um sistema aberto. Nas palavras de Chick (1998, p. 1866), a economia é claramente um sistema aberto, em constante evolução, o que contrasta com os modelos convencionais que são sistemas fechados, autossuficientes e preveem conjunções constantes de eventos.

Para que se consiga produzir regularidades (ou conjunções constantes) de eventos, uma estratégia metodológica é supor o atomismo das entidades teóricas. Lawson (2002, p. 77-78; 1997, p. 77-79) explica que, para se

12 Por dedutivismo entende-se, seguindo Lawson (1997, p. 16-7), a ideia de que a realidade possa ser subsumida a regularidades de eventos (de modo determinista ou estocástico), de forma que explicar um fenômeno é encontrar uma lei geral $\mathrm{X}$ da qual o fenômeno $\mathrm{Y}$ possa ser um consequente, na forma "sempre que X, então Y". 
alcançar alguma regularidade de eventos em uma experiência bem controlada, a entidade deve (i) ser isolada e (ii) ter uma estrutura intrinsecamente estável. Deve ser isolada para evitar que mecanismos contra-atuantes interfiram nos resultados. A metáfora do átomo se destina precisamente a representar qualquer enunciado teórico que postula entidades ou recursos que possuam as propriedades de serem intrinsecamente estáveis e isoladas. A assunção é de que o átomo é semelhante à bola de bilhar, que responde de forma passiva, isto é, de maneira estável e previsível, ao disparo do taco (ou ao ser atingido por outra bola). Claro que, se uma das mãos é colocada sobre a bola, o resultado será afetado. A restrição ou condição de isolamento se destina a evitar esse tipo de interferência. Diante disso, a garantia de regularidades de eventos sociais requer condições análogas às dos estáveis e isolados experimentos controlados em laboratório. Na concepção mainstream, indivíduos são inevitavelmente tratados como atomísticos, de modo que seu comportamento se torna previsível. Para Lawson, esse tipo de teorização reducionista é mais ou menos uma exigência de modelagem econômica formal. A realidade social, no entanto, é bastante diferente (Lawson, 1997, p. 16-19, 91-100; 2002, p. 76-78).

A "dominação epistemológica" da modelagem formal está relacionada diretamente com os currículos dos cursos de economia mais prestigiados que insistem que os métodos formais são a própria matéria da disciplina e que os cursos de economia se reduzem, quase inteiramente, à modelagem formal (Lawson, 2002, p. 78). Além do mais, as nomeações de professores nessas universidades são reservadas a modeladores, e nada é publicado nos periódicos acadêmicos nucleares ou de prestígio se não contiver métodos matemáticos.

A mainstream não reconhece o problema nessa forma usual de teorização na ciência econômica. Eventos como a crise financeira de 2008 são sempre explicados por algum fator exógeno à própria teorização econômica e esta segue incólume em seus métodos formais. Contudo, pode-se defender o argumento de que os problemas teóricos apresentados pela crise financeira recente estão estreitamente relacionados com os supostos ontológicos e metodológicos aceitos por economistas que são, na maioria, da mainstream. Como as estruturas formais são vazias de conteúdo e as estruturas lógicas têm valor de verdade intersubjetivamente demonstrável, teorias construídas dessa maneira geralmente implicam (mesmo que involuntariamente) o sacrifício da relevância em favor de rigor, elegância 
e precisão. Essa é a norma epistêmica adotada que, contudo, é irrelevante para o entendimento da realidade fora do modelo.

O formalismo como um valor epistêmico pode ter sua fonte no ensaio metodológico de Milton Friedman (1953). De acordo com Hands (2009, p. 150-1), "muitos economistas da mainstream sentiram-se 'autorizados' por Friedman para lançarem mão livremente de supostos irrealísticos na construção de modelos econômicos". Em outras palavras, pode-se argumentar que Friedman prestou legitimidade intelectual (i.e., epistêmica) à instituição da ciência econômica em relação ao formalismo. Embora possa ser questionada (e outros fatores estimuladores do formalismo na ciência econômica possam ser apresentados), essa tese não carece de fundamento.

Analisando os impactos do domínio da técnica que se instaurou na ciência econômica, Hodgson (2009, p. 1215-6) também afirma que, para um artigo ser publicado nos principais periódicos, atualmente não é necessário ler ou citar qualquer economista que esteja além do passado recente. Isso ocorre porque a maioria dos economistas está interessada apenas em modelos matemáticos. Como a matemática tem inundado os currículos das principais universidades e escolas de pós-graduação, os alunos de ciências econômicas não foram equipados, nem tampouco encorajados a priorizar, como objeto de estudo, a economia e as instituições do mundo real. As grandes questões, como a natureza e as causas da riqueza e da pobreza das nações, não conferem nenhum prêmio, a menos que se traduzam em análise formal.

Em 1990, apenas 3\% dos alunos de economia dos EUA reconheciam que "ter um conhecimento profundo da economia" seria "muito importante" para o sucesso profissional, ao passo que $65 \%$ achavam que "ser destro, no sentido da capacidade resolver problemas [formais]" era o que importava, conforme o estudo de Klamer e Colander (1990, p. 18 apud Hodgson, 2009, p. 1209). Por fim, 57\% acreditavam que a "excelência em matemática" seria muito importante. Três economistas laureados com o prêmio Nobel manifestaram seu incômodo com a prevalência da matemática sobre os problemas econômicos reais: Wassily Leontief, Ronald Coase e Milton Friedman. ${ }^{13}$ Colander (2009, p. 6) lamenta que nenhum desses alertas gerou qualquer efeito sobre o ensino de pós-graduação em econo13 A posição de Friedman é controversa, como admitimos, mas isso indica que o dedutivismo não assume necessariamente o modo matemático - motivo pelo qual as críticas de Lawson aos métodos matemáticos devem ser qualificadas. Nem a matemática deve ser descartada (ela é útil sempre que os objetos atenderem a certas condições), nem o reducionismo teórico se limita à teorização formalizada. 
mia nos EUA. Blaug (1998, p. 45) diz que havia sido criado "um monstro que não era mais possível deter". Em uma linguagem das instituições da economia, pode-se dizer que se trata de uma norma internalizada pelos atores ou de uma convenção seguida pelos economistas acadêmicos.

É preciso ainda considerar que isso pode ter afetado o julgamento de economistas e, por consequência, os conselhos que deram aos policy makers e ao público antes da crise de 2008 (Hodgson, 2009, p. 1217; Vercelli, 2011, p. 35). Os economistas de finanças são atraídos pelos mercados financeiros graças aos contratos de consultoria lucrativos disponíveis. Tais economistas, de alguma maneira, performam a economia. Ademais, muitas escolas consideram essa atuação no mercado como uma marca de relevância e prestígio. Naturalmente, as escolas mais relevantes e prestigiosas são aquelas com mais capacidade de influenciar a percepção dos agentes econômicos, bem como as mais requisitadas a fornecerem soluções ou darem legitimidade às escolhas de associações, organizações e governos. Uma vez que professores e consultores são posições normalmente imbricadas, os economistas têm pouco "incentivo" para defender maior regulação do sistema financeiro ou mais restrições às corretoras de alto risco, ou para alertar sobre o crescimento do mercado de derivativos e das atividades "fora do balanço". Os interesses ajudaram a manter o status quo tanto acadêmico quanto socioeconômico.

\section{Considerações finais}

Podemos agora juntar os fios do argumento desenvolvido neste trabalho. Os trabalhos recentes nos estudos sociais da ciência têm apontado que os economistas não apenas observam e interpretam o mundo econômico, como também têm um efeito performativo sobre ele. Esse efeito ocorre sempre que algum aspecto das teorias econômicas vem a ser criado no mundo econômico (real, no sentido de externo à atividade científica), tornando-o mais (ou menos) semelhante à sua representação teórica. Uma questão interessante é investigar se a teoria econômica mainstream tem mais efeito performativo ou contraperformativo: isto é, se a introdução de construtos dessa matriz teórica entre as entidades do mundo real tem a capacidade de torná-la mais ou menos útil para iluminar os mecanismos subjacentes ao funcionamento do mundo econômico real. Seja como for, 
essa é uma questão empírica e dependente de casos específicos, o que está fora dos limites deste texto.

Se as ideias dos economistas têm tal poder sobre o mundo em que realmente vivemos, a preocupação que se segue é quanto à origem e à forma de tais ideias. Nosso argumento é que as ideias econômicas não são cogitações imaculadas, mas produtos do que Schumpeter chamou de "visão". Portanto, as teorias econômicas estão carregadas de valores, o que dá uma dimensão moral muito importante à ciência econômica. Quanto ao conteúdo das ideias, argumentou-se que elas são moldadas e desenvolvidas no interior de instituições da ciência econômica. Nessa abordagem institucional, os processos de legitimação epistêmica de teorias têm maior relevância. $\bigcirc$ que a comunidade considera saber legitimo (quer esteja ele voltado à busca do "conceito tradicional" de verdade do qual fala Mäki (2002), quer não) determina o acervo de tais ideias.

$\mathrm{Na}$ moderna mainstream, a formalização matemática tornou-se um valor epistêmico de alta ordem. Embora a formalização matemática não seja um problema cuja solução eliminaria todas as mazelas da teorização econômica, como admitido no texto, ainda assim ela é considerada o valor epistêmico mais relevante para a mainstream, de acordo com autores tanto críticos quanto simpáticos a esse estado de coisas. Se o mundo econômico, intrinsecamente evolutivo e complexo como é, não preencher as condições para que a formalização possa ser um método eficaz para sua representação e interpretação, abrem-se duas possibilidades. Na primeira, o efeito performativo da ciência econômica sobre a economia produz porções do mundo real que se conformam à teoria econômica mainstream. Ainda que tais casos sejam raros, essa possibilidade não significa que a mainstream se tornará, com isso, mais apta a prever, menos ainda explicar os fenômenos do mundo real. $\bigcirc$ exemplo da precificação de títulos pela formula de Fisher Black e Myron Scholes mostra isso com clareza. Introduzida na Bolsa de Chicago e no mundo financeiro, ao longo da década de 1970, ela prometia prever com precisão os preços de derivativos. Amplamente utilizada, a fórmula rendeu a Scholes e a Robert Merton o prêmio Nobel de Economia em 1997. Oito meses depois, a corretora de alto risco (hedge fund) LCTM, dirigida por eles (e outros), perdeu quase US\$ 2 bilhões de capital durante a crise cambial russa e viria a falir dois anos depois. Isso é explicável pela natureza intrinsecamente instável do sistema econômico "fora do modelo", algo que está na "visão" de mundo heterodoxa, mas não na da mainstream. 
A outra possibilidade é que a teoria econômica mainstream possa ter um efeito contraperformativo, isto é, torne-se ainda mais alheia ao funcionamento do mundo econômico real, apesar de introduzir alguns de seus construtos nesse mundo. Um bom exemplo é a liberalização comercial: a experiência brasileira mostra que, em setores altamente oligopolizados e internacionalizados (como o automobilístico), o incentivo à importação pode gerar menos - e não mais - pressões competitivas sobre o mercado doméstico. Neste caso, a contraperformatividade obscurece outros fatores explicativos - possivelmente mais importantes (como a limitada dispersão internacional da P\&D) - do estado de coisas indesejado (viz., a baixa inovatividade das montadoras aqui instaladas). Outro exemplo é que a desregulamentação e o enfraquecimento da supervisão financeira nos EUA, cara à visão laissez-faire implícita nos modelos macroeconômicos da mainstream, aumentou as falhas de mercado, ao reduzir a completude e a confiabilidade da informação (Vercelli, 2011, p. 37).

A conclusão geral é semelhante à de Keynes (1936, p. 383). A tese de performatividade da economia coloca em relevo a importância das teorias econômicas. Boas ou más, elas afetam o mundo socioeconômico que analisam. Isso deveria ser tanto um alerta quanto um incentivo para a construção de teorias que adotem o critério de busca da verdade como ideal regulatório e, assim, para o ensino e uso de teorias com maior chance de serem úteis para o mundo econômico em que realmente vivemos. Como afirma Vercelli (2011, p. 39) sobre a relação entre as teorias macroeconômicas e a economia atual, "acreditamos que não seja possível protelar mais um esforço sistemático na direção de um maior realismo”.

\section{Referências}

ABRAMOVAY, R. Entre Deus e o diabo: Mercados e interação humana nas ciências sociais. Tempo Social, v. 16, n. 2, p. 35-64, 2004.

AUSTIN, J. L. How to do things with words. Oxford: Clarendon Press, 1962.

BADDELEY, M. Herding, social influence and expert opinion. Journal of Economic Methodology, v. 20, n. 1, p. 35-44, 2013.

BARNES, B. Social life as bootstrapped induction. Sociology, v. 17, n. 4, p. 524-545, 1983.

BARNES, B. The nature of power. Cambridge: Polity Press, 1988.

BECKER, G. The economic way of looking at behavior. Journal of Political Economy, v. 101, $\mathrm{n}$. 3, p. 385-409, 1992. 
BIGO, V. Explaining modern economics (as a microcosm of society). Cambridge Journal of Economics, v. 32, n. 4, p. 527-554, 2008.

BLAUG, M. The problems with formalism: Interview with Mark Blaug. Challenge, v. 41, n. 3, p. 35-45, 1998.

BOURDIEU, P. O campo científico. In: ORTIZ, R. (Org.). Pierre Bourdieu. São Paulo: Ática, 1983, 1976. p. 122-155.

BOURDIEU, P. Language and symbolic power. Cambridge: Polity Press, 1991.

CALLON, M. Introduction: The embeddedness of economic markets in economics. In: CALLON, M. (Ed.). The laws of the markets. Oxford: Blackwell, 1998. p. 1-57.

CALLON, M. Why virtualism paves the way to political impotence: A reply to Daniel Miller's critique of The Law of the Markets. Economic Sociology - European Electronic Newsletter, v. 6, n. 2, p. 3-20, 2005.

CALLON, M. What does it mean to say that economics is performative? In: MACKENZIE, D.; MUNIESA, F.; SIU, L. (Eds.). Do economists make markets? On the performativity of economics. Princeton: Princeton University Press, 2007. p. 311-357.

CALLON, M. Performativity, misfires and politics. Journal of Cultural Economy, v. 3, n. 2, p. 163-169, 2010.

CHICK, V. On knowing one's place: The role of formalism in economics. Economic Journal, v. 108, n. 451, p. 1859-1869, 1998.

COLANDER, D. The making of an European economist. Cheltenham: Edward Elgar, 2009.

COLANDER, D.; GOLDBERG, M.; HAAS, A.; JUSELIUS, K.; KIRMAN, A.; LUX, T.; SLOTH,

$B$. The financial crisis and the systemic failure of the economics profession. Critical Review, v. 21, n. 2-3, p. 249-267, 2009.

DAVIS, J. B. The turn in economics and the turn in economic methodology. Journal of Economic Methodology, v. 14, n. 3, p. 275-290, 2007.

DAVIS, J. B.; HANDS, D. W. The elgar companion to recent economic methodology. Cheltenham: Edward Elgar, 2011.

DEQUECH, D. Expectations and confidence under uncertainty. Journal of Post Keynesian Economics, v. 21, n. 3, p. 415-430, 1999.

DEQUECH, D. Conventional and unconventional behavior under uncertainty. Journal of Post Keynesian Economics, v. 26, n. 1, p. 145-168, 2003.

DEQUECH, D. Neoclassical, mainstream, orthodox, and heterodox economics. Journal of Post Keynesian Economics, v. 30, n. 2, p. 279-302, 2007-2008.

DEQUECH, D. Institutions, social norms, and decision-theoretic norms. Journal of Economic Behavior \& Organization, v. 72, n. 1, p. 70-78, 2009.

DEQUECH, D. Economic institutions: Explanations for conformity and room for deviation. Journal of Institutional Economics, v. 9, n. 1, p. 81-108, 2013.

DEQUECH, D. The institutions of economics: A first approximation. Journal of Economic Issues, v. 48, n. 2, p. 523-532, 2014.

DOW, A.; DOW, S. C. Animal spirits revisted. Capitalism and Society, v. 6, n. 2, artigo 1, p. 1-23, 2011. 
FELIN, T.; FOSS, N. Performativity of theory, arbitrary conventions and possible worlds: A realist check. Organization Science, v. 20, n. 3, p. 654-668, 2009.

FRIEDMAN, M. The methodology of positive economics. In: FRIEDMAN, M. Essays in Positive Economics. Chicago: University of Chicago Press, 1953. p. 3-43.

HANDS, D. W. Did Milton Friedman's Methodology License the Formalist Revolution? In: MÄKI, U. (Ed.). The Methodology of Positive Economics: Reflections on the Milton Friedman legacy. Cambridge: Cambridge University Press, 2009. p. 143-164.

HODGSON, G. M. What are institutions? Journal of Economic Issues, v. 40, n. 1, p. 1-25, 2006.

HODGSON, G. M. The Great Crash of 2008 and the Reform of Economics. Cambridge Journal of Economics, v. 33, n. 6, p. 1205-1221, 2009.

HODGSON, G. M. [Reviews of] Donald MacKenzie's An Engine not a Camera... and Material Markets.... Socio-Economic Review v. 8, n. 2, p. 399-410, 2010.

HOOVER, K. D. Microfoundational programs. In: DUARTE, P. G.; LIMA, G. T. (Eds.). Microfoundations reconsidered: The relationship of micro and macroeconomics in historical perspective. Cheltenham: Edward Elgar, 2012. p. 19-61.

KEYNES, J. M. The General Theory of Employment, Interest and Money. Londres: Macmillan. Reimpresso em: Moggridge, D.E. (Ed.). The Collected Writings of John Maynard Keynes, v. 7. Londres: Macmillan, [1936] 1973.

KLAMER, A.; COLANDER, D. The making of an economist. Boulder, CO: Westview Press, 1990.

KNUDSEN, T.; SWEDBERG, R. Capitalist entrepreneurship: Making profit through the unmaking of economic orders. Capitalism and Society, v. 4, n. 2, art. 3, p. 1-26, 2009.

LAWSON, T. Economics and reality. Londres: Routledge, 1997.

LAWSON, T. Mathematical formalism in economics: What really is the problem? In: ARESTIS, P.; DESAI, M.; DOW, S. C. (Eds.). Methodology, microeconomics and Keynes: Essays in honour of Victoria Chick. Londres: Routledge, 2002. p. 73-83.

LAWSON, T. Reorienting economics. Londres: Routledge, 2003.

LAWSON, T. The current economic crisis: Its nature and the course of academic economics. Cambridge Journal of Economics, v. 33, n. 4, p. 759-777, 2009.

MACKENZIE, D. An engine, not a camera: How financial models shape markets. Cambridge, MA: MIT Press, 2006.

MACKENZIE, D.; MUNIESA, F; SIU, L. Introduction. In: MACKENZIE, D.; MUNIESA, F; SIU, L. (Eds.). Do economists make markets? On the performativity of economics. Princeton: Princeton University Press, 2007. p. 1-19.

MÄKI, U. The dismal queen of the social sciences. In: MÄKI, U. (Ed.). Fact and fiction in economics. Cambridge: Cambridge University Press, 2002. p. 3-32.

MÄKI, U. Performativity: Saving Austin from Mackenzie. In: KARAKOSTAS, V.; DIEKS, D. (eds.) Perspectives and foundational problems in Philosophy of Science. Dordrecht: Springer, 2013. p. 443-453.

MORGAN, M. S. The world in the model: How economists work and think. Cambridge: Cambridge University Press, 2012. 
NELSON, R. R.; WINTER, S. G. An evolutionary theory of economic change. Cambridge, MA: The Belknap Press, 1982.

NIINILUOTO, I. Scientific critical realism. Oxford: Oxford University Press, 1999.

NORTH, D. Institutions, institutional change and economic performance. Cambridge: Cambridge University Press, 1990.

NORTH, D. Economic performance through time. American Economic Review, v. 84, n. 3, p. 359-367, 1994.

PALLEY, T. I. Uncertainty, expectations and the future: If we don't know the answers, what are the questions? Journal of Post Keynesian Economics, v. 16, n. 1, p. 3-18, 1993.

PALLEY, T. I. From financial crisis to stagnation: The destruction of shared prosperity and the role of economics. Cambridge: Cambridge University Press, 2012.

PAUlA, J. A.; CROCCO, M.; CERQUeIRA, H. E. A. G.; AlbUQUerQUE, E. M. Conhecimento e interesse em economia. Estudos Econômicos, v. 33, n. 3, p. 559-595, 2003.

SANTOS, A.; RODRIGUES, J. Economics as social engineering? Questioning the Performativity Thesis. Cambridge Journal of Economics, v. 33, n. 5, p. 985-1000, 2009.

SCHUMPETER, J. A. The Theory of Economic Development. Nova York: Oxford University Press, [1934] 1961.

SCHUMPETER, J. A. History of Economic Analysis. Nova York: Oxford University Press, [1954] 1994.

SEARLE, J. The construction of social reality. Londres: Allen Lane, 1995.

SEARLE, J. What is an institution? Journal of Institutional Economics, v. 1, n. 1, p. 1-22, 2005.

SUGDEN, R. Credible worlds: The status of theoretical models in economics. In: MÄKI, U. (Ed.). Fact and fiction in economics: Models, realism and social construction. Cambridge: Cambridge University Press, 2002. p. 107-136.

VERCELLI, A. Economy and economics: The twin crises. In: BRANCACCIO, E.; FONTANA, G. (Eds.). The Global Economic Crisis: New perspectives on the critique of economic theory and policy. Londres: Routledge, 2011. p. 27-41.

\section{Sobre os autores}

\section{Celso NerisJr. -cnerisjr@gmail.com}

Instituto de Economia - Universidade Estadual de Campinas (IE/UNICAMP), Campinas, SP.

JoséRicardo Fucidji - jrfucidji@fclar.unesp.br

Departamento de Economia da UNESP - Campus Araraquara (FCL/UNESP), Araraquara, SP.

Os autores agradecem os comentários e críticas de Fabiano A. Dalto, Gabriel V. Mandarino e Rafael G. Almeida, bem como aos pareceristas anônimos desta revista, eximindo-os de qualquer responsabilidade por erros remanescentes. $O$ segundo autor agradece ainda a FAPESP pelo auxílio (14/22633-8) que possibilitou a apresentação deste trabalho no $42^{\circ}$ Encontro Nacional de Economia.

\section{Sobre o artigo}

Recebido em 25 de julho de 2014. Aprovado em 12 de novembro de 2014. 